\title{
Clinical perspective: monitoring sodium oxybate-treated narcolepsy patients for the development of sleep-disordered breathing
}

\author{
Neil T. Feldman
}

Received: 28 April 2009 /Revised: 24 June 2009 / Accepted: 26 June 2009 /Published online: 23 July 2009

(C) The Author(s) 2009. This article is published with open access at Springerlink.com

\begin{abstract}
Purpose While the symptoms of narcolepsy are often amenable to treatment with sodium oxybate (SXB), the respiratory effects of long-term SXB treatment have not been systematically studied. Recent reports have implicated SXB with several cases of worsening sleep-related breathing disturbances and accidental death. In addition, these patients are at risk for obesity, which may aggravate comorbid obstructive sleep apnea.

Methods Based on a review of the literature and the clinical experience of the author, recommendations for the use of SXB in patients with sleep-disordered breathing have been developed.

Results Among narcolepsy patients with evidence of sleep disordered breathing during baseline polysomnography, SXB should be prescribed only to those patients who fully comply with nasal continuous positive airway pressure therapy. The respiratory status of other SXB-treated patients should be periodically evaluated with nocturnal oximetry. Conclusions Based on the currently available data, physicians prescribing SXB should remain vigilant for the possible development of sleep-disordered breathing during long-term treatment with SXB.
\end{abstract}

Keywords Narcolepsy · Sodium oxybate · Sleep-disordered breathing $\cdot$ Obstructive sleep apnea

N. T. Feldman $(\square)$

St. Petersburg Sleep Disorders Center,

Palms of Pasadena Hospital,

2525 Pasadena Avenue South, Suite S,

St. Petersburg, FL 33707, USA

e-mail: nfeld@msn.com

\section{Introduction}

Narcolepsy is a life-long neurological disorder characterized by excessive daytime sleepiness, cataplexy, and other abnormal expressions of rapid eye movement sleep [1]. It is now believed that the pathophysiology of narcolepsy involves the absence of a fully functional hypocretin signaling system [1]. In addition to frequent awakenings and abnormal REM sleep, the nocturnal sleep of narcolepsy is often further disrupted by obstructive sleep apnea (OSA) which is more common in these patients [2-4]. Additional evidence suggests that the lack of hypocretin predisposes this population to obesity [5-7] which also occurs with significantly greater frequency among patients with narcolepsy. These patients are at risk for further weight gain even after treatment is initiated [8], making OSA more likely to occur over time.

The symptoms of cataplexy and excessive daytime sleepiness are often amenable to treatment with sodium oxybate (SXB) [9]. Based on the results of several level 1 studies [10], SXB is recognized as an effective treatment of cataplexy, daytime sleepiness, and disrupted sleep due to narcolepsy [11]; however, SXB is a central nervous system and respiratory depressant, and these safety issues are described in the product labeling, which includes a black box warning [12].

The use of other central nervous system (CNS) depressants, such as ethanol, has been associated with worsening sleep apnea symptoms [13, 14], and these concerns have recently been extended to include SXB. One recent report described the worsening of sleep-related breathing disturbances during polysomnography in two SXB-treated narcolepsy patients with OSA. One was a 60-year-old woman [body mass index (BMI), 26] who demonstrated an apnea-hypopnea index (AHI) of $8 / \mathrm{h}$ and $10 / \mathrm{h}$ during two 
consecutive nights while taking SXB. These decreased to $3 / \mathrm{h}$ and $6 / \mathrm{h}$ when SXB was discontinued. The other patient was a 58-year-old man (BMI, 32) whose AHI increased from $5 / \mathrm{h}$ and $11 / \mathrm{h}$ on two consecutive nights to $24 / \mathrm{h}$ and $45 / \mathrm{h}$ following the administration of SXB. Following the initiation of nasal continuous positive airway pressure (CPAP), the AHI improved to $1 / \mathrm{h}$ and $3 / \mathrm{h}$. Although these authors suggest that the use of SXB therapy should be initiated in the sleep lab, this precautionary measure cannot predict which patients may develop sleep-disordered breathing with prolonged exposure [15].

Other reports have implicated the use of SXB with fatal outcomes. One report described a 53-year-old woman with sleep apnea who was receiving treatment with nightly SXB for narcolepsy. Concomitant medications included tramadol, gabapentin, cetirizine, modafinil, and carisoprodol. In this case, the combined use of SXB with other CNS depressants was felt to be a contributing factor in her death [16]. Another report also described three deaths associated with the use of SXB. One was clearly an intentional overdose; however, the other two were unexpected deaths than occurred during sleep. One patient was also taking zolpidem and the other was taking alprazolam and quetiapine and was not wearing his CPAP mask [17]. Although the actual cause of death is not known with certainty in all of these cases [18], they raise safety concerns about SXB to a level that requires proactive monitoring of all patients on SXB for the possible development of respiratory depression. An extensive review of post-marketing adverse events associated with SXB including other fatalities is currently in press [19].

To date, only one randomized, placebo-controlled trial has evaluated the use of SXB in patients with OSA. In that study, the use of SXB was associated with statistically but not clinically significant improvements in the AHI of some patients. Three patients experienced clinically significant decreases in arterial oxygen saturation to approximately $55 \%$. In two patients, this decrease was for a brief duration, and they continued SXB treatment without further incident while the third was withdrawn from the trial [20]. Thus, while the use of SXB may slightly improve the AHI in most patients, it appears there may be a subset of patients that are more susceptible to the respiratory depressant effects of SXB. It addition, patient exposure to SXB in this study was limited to 2 weeks. The respiratory effects of long-term SXB treatment have not been systematically studied.

Based on the limited amount of available information, it is clear that a systematic study of the long-term exposure to SXB and patient risk of developing OSA should be undertaken. In the meantime, however, the clinician must take the initiative to carefully monitor these patients for the possible development of worsening sleep-disordered breathing. Obese patients are at significantly greater risk for OSA and need to be aggressively monitored. Each clinician should develop their own standard operating procedure for prescribing SXB to their patients. As a guideline, the author uses the following parameters when prescribing SXB to patients with narcolepsy.

Baseline polysomnography is generally performed in most patients with narcolepsy. If sleep-disordered breathing is present, then SXB should only be prescribed for patients who are fully compliant with nasal CPAP therapy. Although not studied systematically, the author's experience suggests that SXB may improve CPAP compliance in patients with narcolepsy due to improved sleep maintenance. Therefore, the use of SXB should not necessarily be limited to the treatment of narcolepsy patients with only mild OSA; however, patients should be instructed not to take SXB if they do not wear their CPAP mask.

If OSA is not present at baseline, then patients should be followed with nocturnal oximetry as follows:

- Every 2 years for all SXB-treated patients

- Annually for obese patients (BMI, >30)

- Following a 15-lb $(6.8 \mathrm{~kg})$ gain in body weight

- Following an increase in visual analog snoring severity scale score (see Fig. 1)

- When starting a newly prescribed sedating medication which may worsen OSA.

Although there are no available data on the effect of SXB on CPAP pressure requirements, patients on CPAP who are taking SXB should also have periodic oximetric testing. It is the author's opinion that worsening Epworth Sleepiness Scale scores alone should not be used as an indication of the development of OSA in patients taking SXB.

If nocturnal oximetric monitoring on or off nasal CPAP reveals a saw-tooth pattern of oxygen desaturation, patients taking SXB should undergo further evaluation with
Fig. 1 Snoring evaluation questionnaire

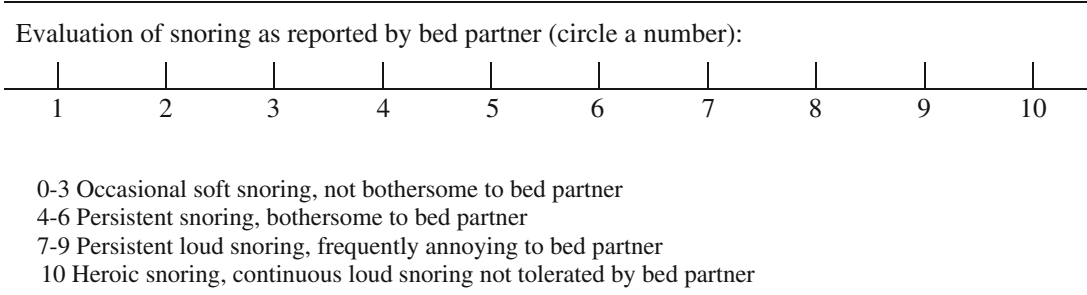


nocturnal polysomnography. The author has observed the development of classic Cheyne-Stokes respiration or periodic breathing in patients taking SXB. If a sustained pattern of desaturation is documented, SXB should be discontinued. Pulmonary function tests should be performed, and a pulmonary consultation for these patients should be considered.

The choice of therapeutic options for the treatment of narcolepsy is limited and leaves many of these patients with a poor quality of life [21]. SXB remains a valuable option for a significant number of patients with narcolepsy. Although the available data is limited, the author suggests that patient safety requires continuing attention to the possible development of sleep-disordered breathing during long-term treatment with SXB.

Open Access This article is distributed under the terms of the Creative Commons Attribution Noncommercial License which permits any noncommercial use, distribution, and reproduction in any medium, provided the original author(s) and source are credited.

\section{References}

1. Nishino S (2007) Clinical and neurobiological aspects of narcolepsy. Sleep Med 8:373-399

2. Wittig R, Zorick F, Piccione P, Sicklesteel J, Roth T (1983) Narcolepsy and disturbed nocturnal sleep. Clin Electroencephalogr 14:130-134

3. Harsh J, Peszka J, Hartwig G, Mitler M (2000) Night-time sleep and daytime sleepiness in narcolepsy. J Sleep Res 9:309-316

4. Plazzi G, Serra L, Ferri R (2008) Nocturnal aspects of narcolepsy with cataplexy. Sleep Med Rev 12:109-128

5. Chabas D, Foulon C, Gonzalez J, Nasr M, Lyon-Caen O, Willer JC, Derenne JP, Arnulf I (2007) Eating disorder and metabolism in narcoleptic patients. Sleep 30:1267-1273

6. Ganjavi H, Shapiro C (2007) Hypocretin/Orexin: a molecular link between sleep, energy regulation, and pleasure. J Neuropsychiatry Clin Neurosci 19:413-419
7. Dahmen N, Becht J, Engel A, Thommes M, Tonn P (2008) Prevalence of eating disorders and eating attacks in narcolepsy. Neuropsychiatr Dis Treat 4:257-261

8. Schuld A, Hebebrand J, Geller F, Pollmächer T (2000) Increased body-mass index in patients with narcolepsy. Lancet 355:1274-1275

9. Robinson D, Keating G (2007) Sodium oxybate: a review of its use in the management of narcolepsy. CNS Drugs 21:337354

10. Wise M, Arand D, Auger R, Brooks S, Watson N, American Academy of Sleep Medicine (2007) Treatment of narcolepsy and other hypersomnias of central origin. Sleep 30:1712-1727

11. Morgenthaler TI, Kapur VK, Brown T, Swick TJ, Alessi C, Aurora RN, Boehlecke B, Chesson AL Jr, Friedman L, Maganti R, Owens J, Pancer J, Zak R (2007) Practice parameters for the treatment of narcolepsy and other hypersomnias of central origin. Sleep 30:1705-1711

12. Xyrem ${ }^{\circledR}$ (sodium oxybate) oral solution. Jazz Pharmaceuticals, Inc., Palo Alto

13. Scanlan M, Roebuck T, Little P, Redman J, Naughton M (2000) Effect of moderate alcohol upon obstructive sleep apnoea. Eur Respir J 16:909-913

14. Peppard P, Austin D, Brown R (2007) Association of alcohol consumption and sleep disordered breathing in men and women. $\mathrm{J}$ Clin Sleep Med 3:265-270

15. Seeck-Hirschner M, Baier P, von Freier A, Aldenhoff J, Göder R (2009) Increase in sleep-related breathing disturbances after treatment with sodium oxybate in patients with narcolepsy and mild obstructive sleep apnea syndrome: two case reports. Sleep Med 10:154-155

16. Akins B, Miranda E, Lacy J, Logan B (2009) A multi-drug intoxication fatality involving Xyrem (GHB). J Forensic Sci 54:495-496

17. Zvosec D, Smith S, Hall B (2009) Three deaths associated with use of Xyrem ${ }^{\circledR}$. Sleep Med 10:490-493

18. Feldman N (2009) Xyrem ${ }^{\circledR}$ safety: the debate continues. Sleep Med 10:405-406

19. Wang YG, Swick, TJ, Carter LP, Thorpy MJ, Benowitz NL (2009). Safety overview of postmarketing and clinical experience of sodium oxybate (Xyrem): abuse, misuse, dependence, and diversion. J Clin Sleep Med (in press)

20. Feldman N, George C (2006) Sleep architecture effects of sodium oxybate treatment in subjects with sleep-disordered breathing. Chest 130:130S

21. Vignatelli L, D'Alessandro R, Mosconi P, Ferini-Strambi L, Guidolin L, De Vincentiis A, Plazzi G (2004) Health-related quality of life in Italian patients with narcolepsy: the SF-36 health survey. Sleep Med 5:467-475 